\title{
Wireless Body Area Networks dan Pengaruhnya dalam Perkembangan Teknologi $m$-Health
}

\author{
Pradini Puspitaningayu, Arif Widodo, Eppy Yundra \\ Jurusan Teknik Elektro, Fakultas Teknik, Universitas Negeri Surabaya \\ pradinip@unesa.ac.id \\ arifwidodo@unesa.ac.id \\ eppyyundra@unesa.ac.id
}

\begin{abstract}
Abstrak - Dunia digital kini telah sampai pada era di mana begitu banyak unsur fisik dapat terhubung dan dimonitor secara jarak jauh dengan penggunaan sensor yang terhubung dalam suatu jaringan komunikasi nirkabel yang berbasis internet (internet of things). Pelayanan kesehatan juga tak luput dari sorotan penggunaan IoT terutama dengan meningkatnya berbagai isu penyakit kronis yang dapat menurunkan harapan hidup manusia. Jaringan yang secara khusus menggunakan berbagai sensor yang ditempatkan pada tubuh manusia ini disebut wireless body area network (WBAN). Artikel ini mengulas tentang bagaimana perkembangan WBAN dalam menjawab berbagai kebutuhan peningkatan layanan kesehatan secara komprehensif dan kontinyu tanpa terhalang keterbatasan jarak dan waktu antara pasien dengan paramedis. Teknologi pemantauan kesehatan yang bersifat mobile ( $m$-Health) terus dikembangkan demi meningkatkan efektivitas dan efisiensi layanan kesehatan. Berbagai isu dan tantangan juga dikemukakan sehingga dapat menjadi telaah referensi untuk berbagai penelitian lanjutan.
\end{abstract}

Kata Kunci: WBAN, IoT, WSN, pelayanan kesehatan, jaringan sensor

\begin{abstract}
The digital world has now arrived in an era where every physical thing can be remotely monitored by using sensors connected to an internet-based wireless communication network (internet of things). Health care services is also become a concern for the development of this service especially because the increasing chronic health problem which can decrease the life expectancy. The network which specifically worked by a set of sensors which attached around human's body is called wireless body area network (WBAN). This article is meant to discuss about the development of WBAN in solving various health care services comprehensively and continuously without any restrictions related to distance and time between the patient and the paramedics. Mobile health monitoring (m-Health) continues to be developed to improve the effectivity and efficiency of health care services. Issues and open challenges are also discussed in the article as a reference for the further researches.
\end{abstract}

Keywords: WBAN, IoT, WSN, health care service, sensor networks

\section{PENDAHULUAN}

Penetrasi teknologi informasi yang meningkatkan transaksi komunikasi digital pada saat ini telah mencakup hampir di semua lini kehidupan manusia [1]. Di sekeliling kita, mulai dari peralatan rumah tangga, kesehatan, hingga gaya hidup. Teknologi komunikasi nirkabel pun saat ini dapat dimanfaatkan untuk pemantauan terhadap parameter tertentu sebagaimana pada wireless sensor network (WSN) yang terdiri dari kumpulan sensor yang mengirimkan data melalui media gelombang radio [2].

WSN telah diaplikasikan secara luas antara lain untuk pertanian [3], struktur bangungan [4], transportasi [5], dan berbagai tujuan lainnya. Teknologi ini sangat erat kaitannya dengan perkembangan Internet of things (IoT), di mana berbagai perangkat komunikasi digital terhubung pada suatu jaringan internet sehingga pertukaran data menjadi jauh lebih mudah dilakukan dengan begitu luas penerapan [6].
Salah satu cabang dari WSN yang secara spesifik berkaitan dengan sensor-sensor yang dipasang di dalam, di permukaan, atau dikenakan oleh manusia disebut wireless body area network (WBAN) [7]. Sebagaimana WSN, WBAN juga memiliki banyak potensi pengembangan yang dapat mengubah paradigma pemantauan parameter vital dalam tubuh manusia yang erat kaitannya dengan kesehatan. Ditambah lagi dengan hubungan eratnya dengan IoT, WBAN berpotensi memberikan layanan monitoring kesehatan jarak jauh, program kebugaan, diagnosis penyakit kronis, dan sebagainya [8]. Gambar 1 berikut ini adalah potensi yang dapat berkembang dari teknologi WBAN.

Teknologi WBAN diterapkan dengan pemasangan sensor di dalam, di permukaan, atau di sekeliling tubuh manusia untuk mendeteksi fungsi vital tertentu yang perlu diamati [9]. Secara spesifik, pada bidang kesehatan, WBAN membawa pengaruh yang signifikan dalam memudahkan pelayanan kesehatan dengan kemampuannya memonitor fungsi vital tubuh manusia 
dan mentransmisikannya melalui media nirkabel. Tingginya tingkat kematian yang disebabkan oleh berbagai penyakit kronis seperti jantung, diabetes, Parkinson, asma, dan berbagai penyakit fatal lainnya dapat diantisipasi dengan deteksi dini dari penggunaan sensor pada tubuh pasien [10]. Teknologi inilah yang kemudian kerap disebut dengan $m$-Health.

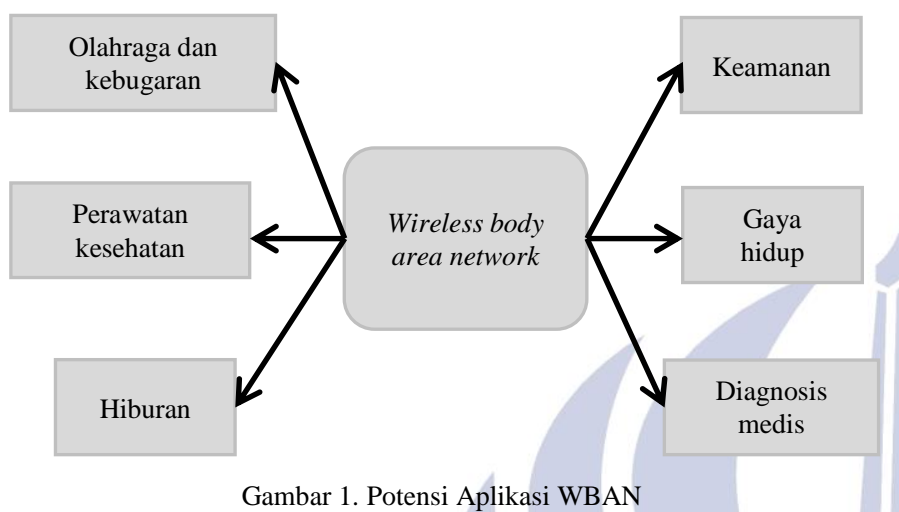

Di bawah naungan standar IEEE 802.15.6 [11], WBAN bekerja dengan prinsip konsumsi daya rendah, bit rate rendah, dan tentunya dengan biaya yang rendah pula. Berkaitan dengan biaya, apabila dibandingkan dengan peralatan/proses diagnosis medis di rumah sakit, penggunaan WBAN dapat memangkas biaya perawatan kesehatan.

Pada tahun-tahun terakhir, aplikasi IoT dan WBAN pada layanan kesehatan telah menarik perhatian banyak pihak [12]. Beragam riset dikembangkan baik dari sisi rekayasa jaringan, metode pengolahan sinyal, pengiriman data, maupun beragam pengembangan aplikasi $m$-Health begitu gencar dilakukan baik dari skala universitas hingga industri. Paper ini membahas berbagai penelitian di bidang WBAN yang secara khusus diperuntukkan pada layanan monitoring kesehatan. Hal tersebut dikarenakan tingginya kebutuhan masyarakat akan peningkatan harapan hidup bagi penderita penyakit-penyakit kronis yang berisiko kematian.

Dengan demikian, diharapkan paper ini dapat menjadi rangkuman dan rujukan bagi penelitian-penelitian berikutnya untuk perluasan mHealth bagi masyarakat.

\section{WIRELESS BODY AREA NETWORK}

Perkembangan pada perangkat komunikasi dalam paradigma IoT berkembang begitu pesat dalam dua dekade terakhir dengan peningkatan penggunaan sensor di setiap aspek kehidupan sehingga membentuk jaringan-jaringan berbasis sensor. Selain itu, didukung dengan perkembangan teknologi komunikasi nirkabel yang mempermudah pengiriman data dengan aksesabilitas yang tinggi seperti Bluetooth, WiFi, ZigBee, dan GSM [13]. Integrasi dari teknologi ini memungkinkan komunikasi data, pemantauan, dan kontrol jarak jauh. Terintegrasinya berbagai unsur fisik ke dalam sistim berbasis komputer ini dapat secara signifikan mempermudah berbagai aplikasi penginderaan atau pemantauan secara kontinyu tanpa terikat dengan jarak.

Teknologi jaringan sensor nirkabel ini tak hanya diterapkan pada benda-benda mati, namun ada pula yang secara spesifik dipasang pada pakaian, permukaan, maupun dimasukkan ke dalam tubuh makhluk hidup, khususnya manusia. Sensorsensor yang dapat mengirimkan data secara nirkabel ini dipasang dengan tujuan untuk meningkatkan berbagai layanan kesehatan dan juga meningkatkan kualitas hidup [14]. Teknologi inilah yang secara spesifik disebut wireless body area network (WBAN).

Sensor-sensor yang terpasang pada tubuh disebut nodes, dimana pengiriman data dari masing-masing node tersebut dilakukan dalam jarak dekat yaitu sekitar 2-10 meter sebagaimana standar komunikasi untuk wireless personal area networks (WPAN) [15]. Namun, perpedaan antara WBAN dan WPAN terletak pada tujuan utama dari kedua jaringan tersebut. Jika WPAN bertujuan untuk menghubungkan perangkat komunikasi data personal dalam lingkup umum, WBAN secara spesifik menarget aplikasi-aplikasi yang berhubungan dengan manusia antara lain: pelayanan kesehatan, pelatihan olahraga, navigasi, keamanan kerja, hiburan, hingga perlindungan militer.

Untuk memonitor parameter-parameter vital pada tubuh, WBAN tersusun dalam arsitektur yang terdiri dari sensorsensor yang disebut nodes, chip mikrokontroller, modul komunikasi nirkabel, dan perangkat-perangkat komunikasi data yang terhubung pada jaringan tertentu misal pelayanan rumah sakit. Gambar 2 di bawah ini merupakan ilustrasi dari arsitektur WBAN [16].

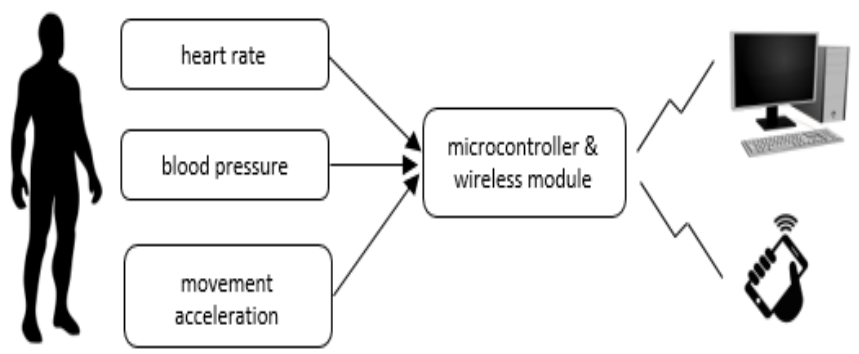

Gambar 2. Arsitektur WBAN sederhana

Tingkatan pertama dalam arsitektur WBAN adalah pada sisi pengguna, dimana sensor-sensor dengan kemampuan untuk melakukan sampling, pemrosesan, dan komunikasi dengan satu atau lebih tanda-tanda vital tubuh (detak jantung, tekanan darah, kadar oksigen, aktivitas) atau parameter lingkungan (lokasi, temperatur, kelembaban, cahaya) yang ditempatkan pada tubuh dalam bentuk lempengan kecil maupun dimasukkan 
dalam pakaian sehari-hari sehingga memungkinkan pemantauan 24/7 pada parameter yang dibutuhkan [17].

Kedua, perangkat mikrokontroler yang sekaligus merupakan server personal berfungsi sebagai penghubung, antarmuka, dan sarana komunikasi ke jaringan tahap akhir. Perangkat ini dapat berupa personal digital assistant (PDA) maupun telepon selular, dan bisa juga menggunakan komputer pribadi. Pada hirarki ini, komunikasi dari sensor ke koordinator jaringan umumnya dilakukan menggunakan standar ZigBee atau Bluetooth. Sementara itu, komunikasi dari koordinator ke server akhir layanan dapat memanfaatkan jaringan selular (EDGE, HSPA, LTE) maupun layanan penyedia internet lainnya.

Jenis sensor yang umumnya digunakan pada WBAN contohnya electrocardiogram (ECG), electromyogram (EMG), electroencephalogram (EEG), sensor detak jantung, pendeteksi glukosa dalam darah, pengukur kadar oksigen dalam darah, accelerometer, gyroscope, magnetometer, GPS, dan lain-lain. Dari penggunaan sensor-sensor tersebut, maka WBAN begitu erat kaitannya dengan sistim monitoring pada layanan kesehatan yang bersifat mobile, remote access, dan kontinyu.

Sebagai tambahan, saat ini dengan perkembangan pesat ponsel cerdas (smartphone) juga turut mendukung pertumbuhan aplikasi-aplikasi jaringan sensor nirkabel yang terkait dengan kesahatan. Kemudian, dengan adanya smartphone yang sudah dilengkapi dengan berbagai sensor (contoh: accelerometer, gyroscope, GPS, dll), fungsi pemantauan kesehatan dapat dilakukan dalam satu perangkat sekaligus. Dimulai dengan pembacaan tanda-tanda vital oleh sensor-sensor pada smartphone, pemrosesan sinyal, diagnosis, hingga layanan data ke jaringan yang lebih luas sebagai tindak lanjut dari kebutuhan layanan.

\section{TREN APLIKASI WBAN DALAM LAYANAN KESEHATAN}

Meningkatnya jumlah penderita penyakit kronis berisiko fatal sebagaimana disebutkan dalam pendahuluan menginspirasi para peneliti dari berbagai kalangan untuk membuat suatu sistim monitoring kesehatan yang dapat dilakukan kapan dan di mana saja. Adanya teknologi WBAN yang bekerja unutk mendeteksi parameter-parameter tubuh, perkembangan WBAN banyak diaplikasikan dalam layanan kesehatan. Gambar 3 adalah bentuk lebih luas dari penerapan WBAN dalam pelayanan kesehatan.

Sementara itu, secara spesifik pengembangan $m$-Health saat ini banyak difokuskan untuk pasien-pasien dengan penyakit kronis yang dapat sewaktu-waktu terjadi kondisi gawat darurat. Dengan pengamatan sinyal dari sensor-sensor tertentu, sebagaimana diilustrasikan pada gambar 3, parameter vital tersebut dapat memiliki fungsi diagnosis awal, terhubung dengan rumah sakit, dokter dan paramedic, serta cakupan hingga jaringan cloud.

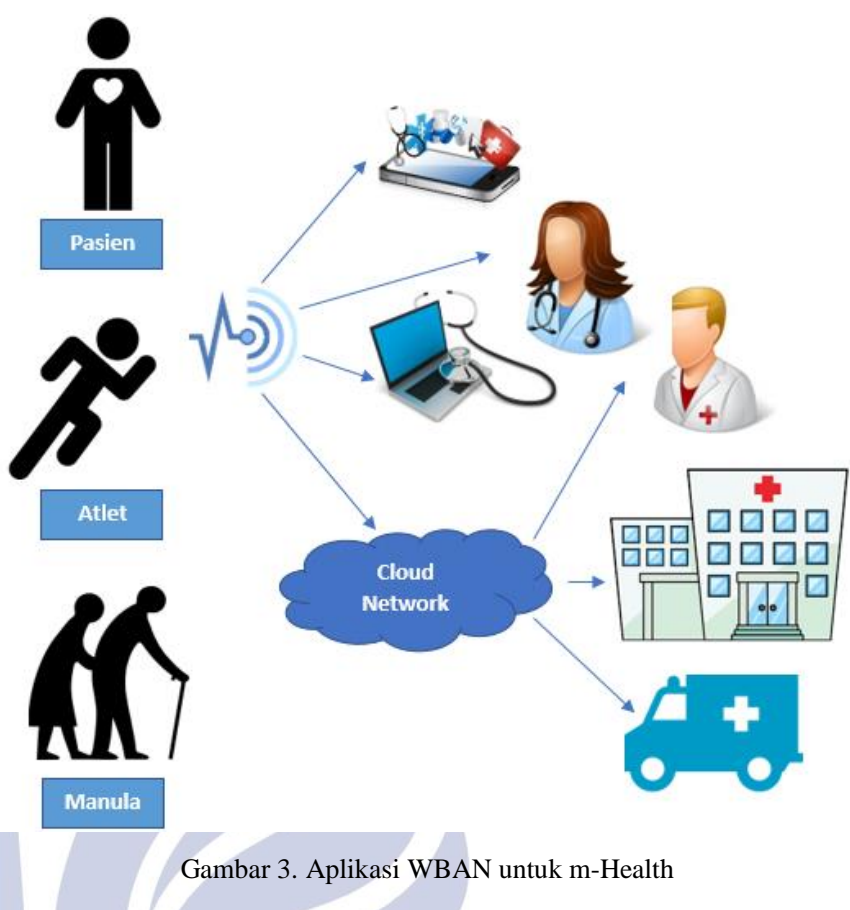

Berikut ini adalah penyakit-penyakit kronis yang menjadi perhatian dalam penggunaan jaringan sensor nirkabel:

\section{Gangguan Kardiovaskular}

Sebagai pembunuh nomor satu di dunia, penyakit jantung menjadi perhatian nomor satu dalam aplikasi layanan kesehatan. Penggunaan sensor electrocardiograph (ECG) dan pendeteksi kecepatan detak jantung sering diaplikasikan dalam fokus riset bentuk mulai dari desain sistim, mekanisme komunikasi dalam jaringan, hingga desain antena sebagai salah satu komponen utama dalam komunikasi nirkabel[18][19][20][21][22]. Pembacaan sinyal detak jantung yang diintegrasikan dengan kemampuan diagnosis dan deteksi dini, kemudian dihubungkan dengan aktuator yang dapat memberikan notifikasi dan peringatan awal baik kepada pengguna, keluarga, rumah sakit, maupun dokter [18][19][22].

Penggunaan sensor ECG untuk monitoring fungsi jantung juga bisa dikombinasikan dengan sensor lain seperti accelerometer [20] sebagai parameter aktivitas pasien. Sementara itu, deteksi detak jantung selain menggunakan sensor ECG juga dapat dilakukan dengan sensor photoplesthysmograph [23]. Sensor ini bekerja dengan melakukan pembacaan ritme jantung melalui variasi reaksi jaringan biologis terhadap cahaya yang ditembakkan dengan metode refleksi (sebagai contoh pada permukaan jari) atau dengan metode transmisi (sebagai contoh melalui lubang telinga). 


\section{Penyakit Parkinson}

Parkinson adalah suatu penyakit yang secara progresif menyerang sistim syaraf di mana penderita mengalami tremor, kaku, dan ketidakstabilan postur [24]. Perlunya pengawasan terhadap penderita Parkinson dalam aktivitas keseharian kemudian menjadi perhatian khusus dalam penerapan teknologi WBAN. Karena berkaitan dengan fungsi gerak anggota tubuh, peneliti umumnya menggunakan sensor inersial seperti accelerometer dan gyroscope sebagai pendeteksi gerakan tubuh pasien [25][26][27].

Secara spesifik, Cancela dkk [25], selain menggunakan sensor-sensor yang dikenakan pada tubuh, juga mengombinasikan analisis pergerakan dengan menempelkan sensor-sensor pada dinding rumah untuk meningkatkan keleluasaan dan kemandirian pasien penderita Parkinson saat bergerak di dalam rumah.

\section{Diabetes}

Berikutnya, diabetes sebagai penyakit kronis yang semakin banyak dialami masyarakat dunia pun turut mendapat perhatian. Penggunaan sensor pendeteksi glukosa dalam darah digunakan untuk memantau pola perubahan kadar gula seorang pasien [28][29][30].

Karakteristik pola gula darah ini kemudian juga dapat dikembangkan menjadi perencanaan diet, aktivitas, dan konsumsi obat yang lebih sesuai kebutuhan personal.

\section{Rehabilitasi Fisik}

Selain pengobatan dan tindakan medis, beberapa kasus seperti kecelakaan, cedera, atau pascaoperasi, pasien memerlukan rehabilitasi untuk pemulihan kondisi dan fungsi tubuh. Dengan bantuan sensor-sensor yang dipasang pada tubuh, baik pasien, paramedis, dan keluarga dapat dimudahkan dalam memantau perkembangan proses rehabilitasi. E Jovanov dkk pada [31] mengembangkan set sensor yang terdiri dari accelerometer dan sensor ECG sebagai pembaca aktivitas, yang kemudian disebut ActiS. Sensor ini dipasang ke tubuh pasien untuk memonitor aktivitasnya selama rehabilitasi fisik dengan - membaca percepatan gerakan dan faktor fisiologis dari grafik kardiovaskular.

Sementara itu, Hu dkk juga mengimplementasikan WBAN dengan beberapa sensor yang dapat mengidentifikasi postur tubuh manusia dalam keadaan berjalan, lari, jongkok, dan duduk [32]. Aplikasi ini ditujukan agar dokter dapat memonitor aktivitas fisik dan menganalisis postur tubuh pengguna.

Dengan demikian, WBAN yang dipasang pada tubuh pasien cukup menjajikan untuk program monitoring dan diagnosis jarak jauh secara lebih efektif dan efisien selama menjalani tahap rehabilitas medis [33].

\section{Berbagai Macam Gejala Fisiologis}

Selain beberapa kategori yang secara spesifik disebutkan sebelumnya, WBAN juga dapat diaplikasikan untuk pengamatan gejala atau reaksi tertentu pada tubuh yang dapat mengindikasikan kondisi penyakit tertentu. Jenis aplikasi yang dikembangkan antara lain pengamatan tekanan darah sebagaimana pada [34] dengan menggunakan alat pengukur tekanan darah yang dilengkapi dengan modul komunikasi nirkabel.

Pengamatan suhu tubuh, dan kadar oksigen dalam darah, sebagai parameter tanda-tanda vital dari kondisi kesehatan seseorang juga menjadi perhatian pada pengembangan sistim monitoring kesehatan. Suatu bentuk implementasi WBAN dikembangkan pada [35] untuk memantau suhu tubuh, detak jantung, dan konsentrasi oksigen dalam darah. Sensor-sensor ini terhubung dengan modul nirkabel ZigBee sebagai media transmisi. Berikutnya, inovasi untuk pengamatan serupa dilakukan pada [36] dengan menambahkan kemampuan koneksi dengan database pada cloud server dan sms gateway sebagai notifikasi jika terjadi kondisi gawat darurat.

Dari berbagai macam tanda-tanda vital pada tubuh, teknologi ini kemudian dikembangkan menjadi suatu model pengendalian wabah penyakit berdasarkan kluster [37][38] berbasis aktivitas pengguna smartphone. Pengumpulan data dilakukan sebagai berikut: 1) smartphone merekam informasi sosial pengguna meliputi pergerakan dan durasi interaksi sosial, 2) sensor-sensor yang terpasang pada tubuh membaca tandatanda vital seperti tekanan darah, detak jantung, dan suhu tubuh, 3) smartphone juga berperan sebagai gateway WBAN, 5) semua informasi akan dikirim ke smartphone dan diteruskan ke pusat kontrol.

\section{TANTANGAN PADA APLIKASI M-HEALTH}

Dalam penerapan WBAN untuk berbagai aplikasi layanan kesehatan, terdapat beberapa tantangan yang terus-menerus dikembangkan dan diinovasi oleh para peneliti dalam meningkatkan efektivitas dan efisiensi jaringan untuk mendukung fungsi dan tujuan yang diharapkan.

\section{Konsumsi Daya}

Sebagaimana pada teknologi wireless sensor network yang terhubung 24/7 dengan jaringan internet, manajemen konsumsi daya juga menjadi tantangan utama yang terus diteliti. Pendekatan efisiensi konsumsi daya dilakukan dari berbagai lapisan mulai dari inovasi desain antena [19][39], desain topologi jaringan [40], rekayasa lapisan medium access control (MAC) [41][42], efisiensi mekanisme routing [43][44][45], hingga gagasan-gagasan mengenai energi terbarukan (energy harvesting) dalam aplikasinya untuk WBAN [46][47]. 
Permasalahan konsumsi daya ini harus diperhatikan dalam penerapan WBAN dikarenakan sensor-sensor yang terusmenerus aktif rentan mengalami kegagalan komunikasi karena kapasitas baterai yang terbatas. Dengan demikian, perlu dilakukan manajemen khusus sehingga pengiriman data dapat secara maksimal bersifat hemat daya namun tanpa mengurangi sedikitpun informasi yang perlu dimonitor.

Kondisi fatal yang dapat muncul manakala terjadinya putus komunikasi adalah jika bersamaan dengan pasien mengalami kegawatdaruratan. Maka, fungsi yang semestinya dapat diantisipasi dengan penggunaan WBAN dapat mengalami kegagalan dan berdampak pada kondisi pasien.

\section{Keamanan Data Pribadi}

Dalam penerapan teknologi IoT pada bidang apapun, perlindungan privasi menjadi salah satu konsekuensi yang harus diperhatikan. Terutama jika berhubungan dengan riwayat medis seseorang. Dengan demikian, dalam teknologi mHealth, perlindungan privasi harus terus ditingkatkan.

Sebagaimana halnya dengan permasalahan energi yang dikemukakan sebelumnya, keamanan akses data pada WBAN juga telah dilakukan pada berbagai aspek meliputi skema kriptografi data [48], otentifikasi di sisi pengguna yang dapat mengakses jaringan [49], dan keamanan protokol [50].

Privasi pengguna harus sangat diperhatikan karena besarnya kemungkinan serangan terjadi pada jaringan sensor ini. Ancaman dapat berasal dari luar maupun dari dalam jaringan. Kegiatan pengintaian data pribadi baik terkait kondisi vital maupun aktivitas seseorang secara diam-diam harus diwaspadai untuk menjamin keamanan pengguna produk mHealth.

Peningkatan keamanan dapat terus dilakukan pada berbagai lapisan komunikasi baik pada sisi aplikasi layanan, keamanan data, berbagai metode enkripsi jaringan, dsb. Namun, penerapan strategi kemanan tersebut juga tidak boleh membebani jaringan karena terikat dengan syarat WBAN yang harus bersifat low-power dan low-bit rate karena sistim keamanan sering kali berbanding terbalik dengan efisiensi penggunaan kanal komunikasi sehingga dapat mengurangi kualitas layanan.

\section{Keandalan Jaringan Komunikasi}

Pada penerapan WBAN, sangat memungkinkan dalam satu tubuh terpasang beberapas sensor sekaligus. Tantangan yang muncul kemudian adalah bagaimana masing-masing sensor dapat berkomunikasi dengan terminal tanpa ada interferensi satu sama lain.

Terlebih lagi, masing-masing sensor tersebut juga disyaratkan untuk beroperasi dengan konsumsi daya yang rendah, maka faktor atenuasi atau pelemahan sinyal harus diminimalisasi dengan penempatan titik yang tepat. Tanpa strategi rekayasa jaringan yang baik, maka kualitas sinyal WBAN tidak akan cukup untuk memenuhi syarat minimal validitas data medis yang dibutuhkan.

Beberapa riset terkait keandalan jaringan komunikasi pada WBAN meliputi strategi penempatan titik sink yang menjadi muara data-data yang dikirim dari berbagai sensor yang digunakan [51]. Penempatan titik sink ini menggunakan strategi satu lompatan, di mana sensor langsung mengirim data ke satu sink untuk kemudian diteruskan ke perangkat komunikasi berikutnya.

Berikutnya, upaya peningkatan kualitas komunikasi juga dilakukan dengan model geometri stokastik [52]. Karena setiap titik dapat saling mendengarkan apakah titik lain sedang mengirimkan informasi, maka strategi carrier-sensing bersama dan daya pengiriman informasi diterapkan untuk meningkatkan keseluruhan throughput dan mengurangi interferensi.

Selain parameter-parameter jaringan yang telah disebutkan, tantangan lain yang harus diperhatikan adalah skalabilitas. Dengan terus bertambahnya titik-titik yang diamati dengan sensor, penambahan otoritas yang dapat terhubung ke dalam jaringan, serta jenis aplikasi, maka jaringan sensor yang dikembangkan harus mudah dikembangkan dari sisi keluasan cakupan jaringan maupun

\section{PENUTUP}

\section{Simpulan}

Dengan meningkatnya kebutuhan layanan kesehatan di masyarakat, WBAN dapat menjadi pengubah paradigma bahwa monitoring kesehatan dapat dilakukan tanpa dibatasi oleh jarak dan waktu. Pengembangan $m$-Health dapat menjawab berbagai kebutuhan dan keterbatasan yang dimiliki baik oleh pasien maupun tenaga medis. Selain itu, dengan monitoring yang dilakukan dalam 24/7 dapat meningkatkan akurasi diagnosis serta memberikan peringatan dini jika terjadi kondisi gawat darurat pada pasien.

Layanan $m$-Health yang dikembangkan saat ini meliputi berbagai konsentrasi seperti gangguan kardiovaskular, Parkinson, diabetes, rehabilitasi fisiologis, dan berbagai kebutuhan deteksi tanda-tanda vital pada tubuh (temperatur, tekanan darah, saturasi oksigen dalam darah, dll). Selain itu, layanan kesehatan juga dapat mencakup pemantauan aktivitas fisik, lokasi pergerakan, dan interaksi sosial untuk pengendalian wabah penyakit tertentu.

Meski demikian, dibalik berbagai keluasan manfaat dan aplikasi WBAN, teknologi ini juga disertai dengan berbagai tantangan yang harus dipenuhi terkait sederetan syarat yang diatur dalam standar IEEE 802.15.6. Tantangan yang dihadapi dalam pengembangan WBAN untuk $m$-Health antara lain meliputi penghematan dan efisiensi penggunaan daya, privasi 
dan keamanan data, skalabilitas jaringan, serta berbagai parameter kualitas layanan (QoS). Semua faktor tersebut harus dapat dijamin dalam pengembangan jaringan sensor untuk pelayanan kesehatan.

\section{Saran}

Berdasarkan ulasan mengenai penerapan WBAN dalam layanan kesehatan, penelitian dapat dilanjutkan untuk menjawab berbagai tantangan meliputi perluasan aplikasi untuk penyakit kronis lain, efisiensi daya, peningkatan privasi dan keamanan data, peningkatan parameter-parameter keandalan komunikasi, dan berbagai tantangan yang mungkin muncul dalam pelayanan kesehatan dengan jaringan sensor nirkabel.

\section{DAFTAR PUSTAKA}

[1] N Bui et al. 2017. "A Survey of Anticipatory Mobile Networking: Context-Based Classification, Prediction Methodologies, and Optimization Techniques". IEEE Communications Surveys \& Tutorials (Volume: 19, Issue: 3 )

[2] I Tomic, JA McCann. 2017. "A Survey of Potential Security Issues in Existing Wireless sensor network Protocols". IEEE Internet of things Journal (Volume: PP, Issue: 99)

[3] Q Chen et al. 2013. "Improved relay node placement algorithm for Wireless sensor networks application in Wind Farm". IEEE International Conference on Smart Energy Grid Engineering (SEGE)

[4] AB Noel et al. 2017. "Structural Health Monitoring Using Wireless sensor networks: A Comprehensive Survey". IEEE Communications Surveys \& Tutorials (Volume: 19, Issue: 3 )

[5] E Aguirre et al. 2017. "Design and Implementation of Context Aware Applications with Wireless sensor network Support in Urban Train Transportation Environments". IEEE Sensors Journal (Volume: 17, Issue: 1)

[6] M Marjani et al. 2017. "Big IoT Data Analytics: Architecture, Opportunities, and Open Research Challenges". IEEE Access Volume: 5 pp 5247-5261

[7] Kiran, P Ahlawat. 2015. "A Review on Wireless body area network". IJSER Volume 3 Issue 6 pp 72-75

[8] SMR Islam, et al. 2015. "The Internet of things for Health Care: A Comprehensive Survey". IEEE Access Volume 3 pp 678-708

[9] B Johny, A Anpalagan. 2014. "Body area sensor networks: requirements, operations, and challenges". IEEE Magazine March/April pp 21-25

[10] S Movassaghi, J Lipman. 2013. "Wireless body area networks: A Survey". IEEE Communication Surveys and Tutorials

[11] "IEEE standard for local and metropolitan area networks: Part 15.6: Wireless body area networks," IEEE submission, Feb. 2012

[12] T Wu et al. 2017. "An Autonomous Wireless body area network Implementation Towards IoT Connected Healthcare Applications". IEEE Access (Volume: 5) pp 11413 - 11422

[13] M Marjani et al. 2017. "Big IoT Data Analytics: Architecture, Opportunities, and Open Research Challenges". IEEE Access Volume: 5

[14] B Latre et al. 2011. "A survey on wireless body area networks". Wireless Network Volume 17, Issue 1, pp 1-18

[15] $\mathrm{H}$ Cao et al. 2009. "Enabling technologies for wireless body area networks: A survey and outlook". IEEE Communication Magazine Volume 47 Issue 12

[16] P Puspitaningayu et al. 2017. "The Emerging Wireless body area network on Android Smartphones: A Review". The $2^{\text {nd }}$ Annual Applied Science and Engineering Conference, Bandung, Indonesia
[17] C Otto et al. 2006. "System Architecture of a Wireless Body Area Sensor Network for Ubiquitous Health Monitoring”. Journal of Mobile Multimedia, Vol. 1, No 4, pp 307-326

[18] V Wahane, PV Ingole. 2016. "An Android Based Wireless ECG Monitoring System for Cardiac Arrhythmia". IEEE Healthcare Innovation Point-of-Care Technologies Conference (POCT) pp 183 187

[19] G Wolgast et al. 2016. "Wireless body area network for Heart Attack Detection”. IEEE Antennas \& Propagation Magazine October 2016 pp 84-91

[20] E Kańtoch et al. 2011. "Wireless body area network System based on ECG and Accelerometer Pattern". Computing in Cardiology 38:245248

[21] FA Khan et al. 2017. "A Continuous Change Detection Mechanism to Identify Anomalies in ECG Signals for WBAN-Based Healthcare Environments". IEEE Access Volume: 5 pp 13531-13544

[22] P Prittopaul et al. 2015. "Cyber Physical System approach for heart attack detection and control using wireless monitoring and actuation system". IEEE 9th International Conference on Intelligent Systems and Control (ISCO)

[23] AR Maria et al. 2017. "Heart Rate Monitoring by using Non-invasive Wearable Sensor". The $6^{\text {th }}$ International Conference on E-Health and Bioengineering pp 587-590

[24] Tugwell, C. 2008. "Parkinson's Disease in Focus". Pharmaceutical Press: London, UK

[25] J Cancela et al. 2014. "Feasibility Study of a Wearable System Based on a Wireless body area network for Gait Assessment in Parkinson's Disease Patients". Sensors Volume: 14(3) pp 4618-4633

[26] R. Contreas et al. 2016. "Tremors Quantification in Parkinson Patient Using Smartwatches”. IEEE Ecuador Technical Chapters Meeting pp 1-6

[27] L Li et al. 2017. "Multi-sensor wearable devices for movement monitoring in Parkinson's disease". 8th International IEEE/EMBS Conference on Neural Engineering (NER)

[28] R. S. H. Istepanian et al. 2011. "The potential of Internet of m-health Things 'm-IoT' for non-invasive glucose level sensing,' in Proc. IEEE Annu. Int. Conf. Eng. Med. Biol. Soc. (EMBC), Aug./Sep. 2011, pp. 5264-5266

[29] ZJ Guan. 2013. "Somatic data blood glucose collection transmission device for Internet of things," Chinese Patent $202838653 \mathrm{U}$

[30] L Wei,Y Heng, and WY Lin. 2012. "Things based wireless data transmission of blood glucose measuring instruments, 'Chinese Patent 202154684 U

[31] E Jovanov et al. 2005. "A Wireless body area network of Intelligent Motion Sensors for Computer Assisted Physical Rehabilitation”. Journal of NeuroEngineering and Rehabilitation

[32] F Hu et al. 2016. "A Human Body Posture Recognition Algorithm Based on BP Neural Network for Wireless body area networks". Chinese Communication pp 198-208

[33] B Tan dan O Tian. 2014. "Short paper: Using BSN for tele-health application in upper limb rehabilitation'. Proc. IEEE World Forum Internet Things (WF-IoT) pp. 169-170

[34] M Singh dan N Jain. 2016. "Performance and Evaluation of Smartphone based Wireless Blood Pressure Monitoring System using Bluetooth". IEEE Sensors Journal

[35] MUH Al Rasyid et al. 2015. "Wireless body area network for monitoring body temperature, heart beat and oxygen in blood". Proc of International Seminar on Intelligent Technology and Its Application (ISITIA)

[36] RMD Omer and NK Al Salihi. 2017. "HealthMate: Smart Wearable System for Health Monitoring (SWSHM)". Proc of IEEE 14 International Conference on Networking, Sensing and Control (ICNSC)

[37] H Wang et al. 2014. "Socialized WBANs in Mobile Sensing Environments". IEEE Network September/October pp: 91-95

[38] Z Zhang et al. 2015. "Cluster-based Epidemic Control Through Smartphone-based Body Area Networks". IEEE Transactions on Parallel and Distributed Systems

[39] E Reusens et al. 2009. "Characterization of On-Body Communication Channel and Energy Efficient Topology Design for Wireless body area networks". IEEE Transactions on Information Technology in Biomedicine, Volume: 3, Issue: 6 
[40] W Joseph et al. 2011. "Design of Energy Efficient Topologies for Wireless On-Body Channel". Wireless Conference - Sustainable Wireless Technologies

[41] B Liu et al. 2015. "Medium Access Control for Wireless body area networks with QoS Provisioning and Energy Efficient Design". IEEE Transactions on Mobile Computing

[42] S Moulik et al. 2016. "AT-MAC: Adaptive MAC-Frame Payload Tuning for Reliable Communication in Wireless body area networks". IEEE Transactions on Mobile Computing Volume: 16, Issue: 6, pp 1516-1529

[43] H Moungla et al. 2013. "Efficient heterogeneous communication range management for dynamic WBAN topology routing". Proc of Future Information and Communication for Ubiquitous HealthCare

[44] P Mohnani dan F Jabeen. 2016. "Power efficient, reliable and secure wireless body area network". Proc of 3rd International Conference on Computing for Sustainable Global Development (INDIACom) pp 2722-2726

[45] M Roy et al. 2017. "Designing an energy efficient WBAN routing protocol". Proc of 9th International Conference on Communication Systems and Networks (COMSNETS), pp: 298-305

[46] Z Ling et al. 2017. "Point-to-Point Wireless Information and Power Transfer in WBAN With Energy Harvesting”. IEEE Access Volume: 5, pp: $8620-8628$

[47] H Mosavat-Jahromi et al. 2017. "Maximizing Spectral Efficiency for Energy Harvesting-Aware WBAN". IEEE Journal of Biomedical and Health Informatics Volume: 21, Issue: 3, pp: 732-742

[48] A Ara et al. 2017. "A Secure Privacy-Preserving Data Aggregation Scheme Based on Bilinear ElGamal Cryptosystem for Remote Health Monitoring Systems". IEEE Access, Volume: 5, pp 12601-12617

[49] H Xiong, Z Qin. 2015. "Revocable and Scalable Certificateless Remote Authentication Protocol with Anonymity for Wireless body area networks". IEEE Transactions on Information Forensic and Security, Volume: 10, Issue: 7, pp 1442-1455

[50] C Hu et al. 2016. "Secure and Efficient Data Communication Protocol for Wireless body area networks". IEEE Transactions on Multi-Scale Computing Systems, Volume: 2, Issue: 2, pp 94-107

[51] F Yong et al. 2014. "Sink Node Placement Strategy for Wireless body area networks". Proc of The 12th International Conference on Signal Processing

[52] R Liu. 2017. "Throughput assurance of wireless body area networks coexistence based on stochastic geometry". PLOS ONE Volume: 12

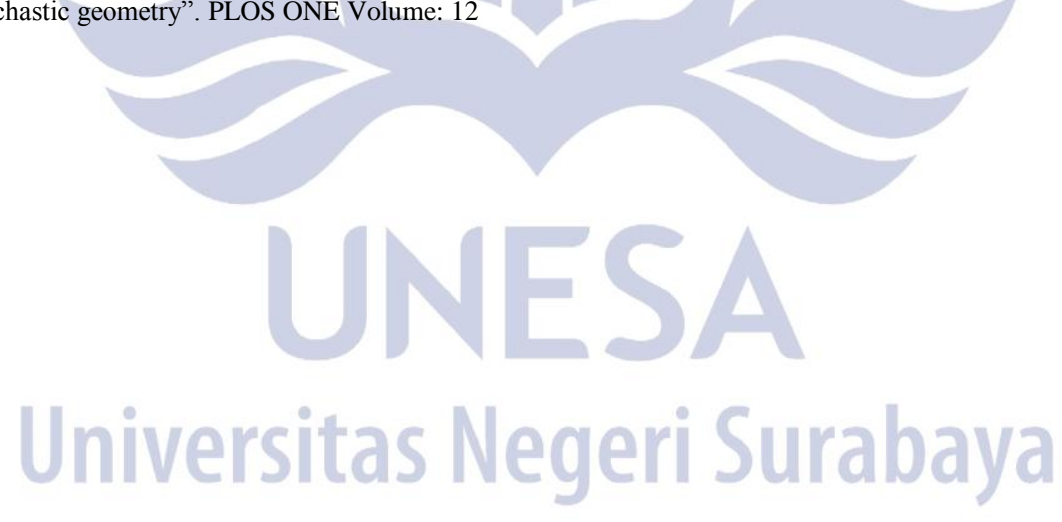

